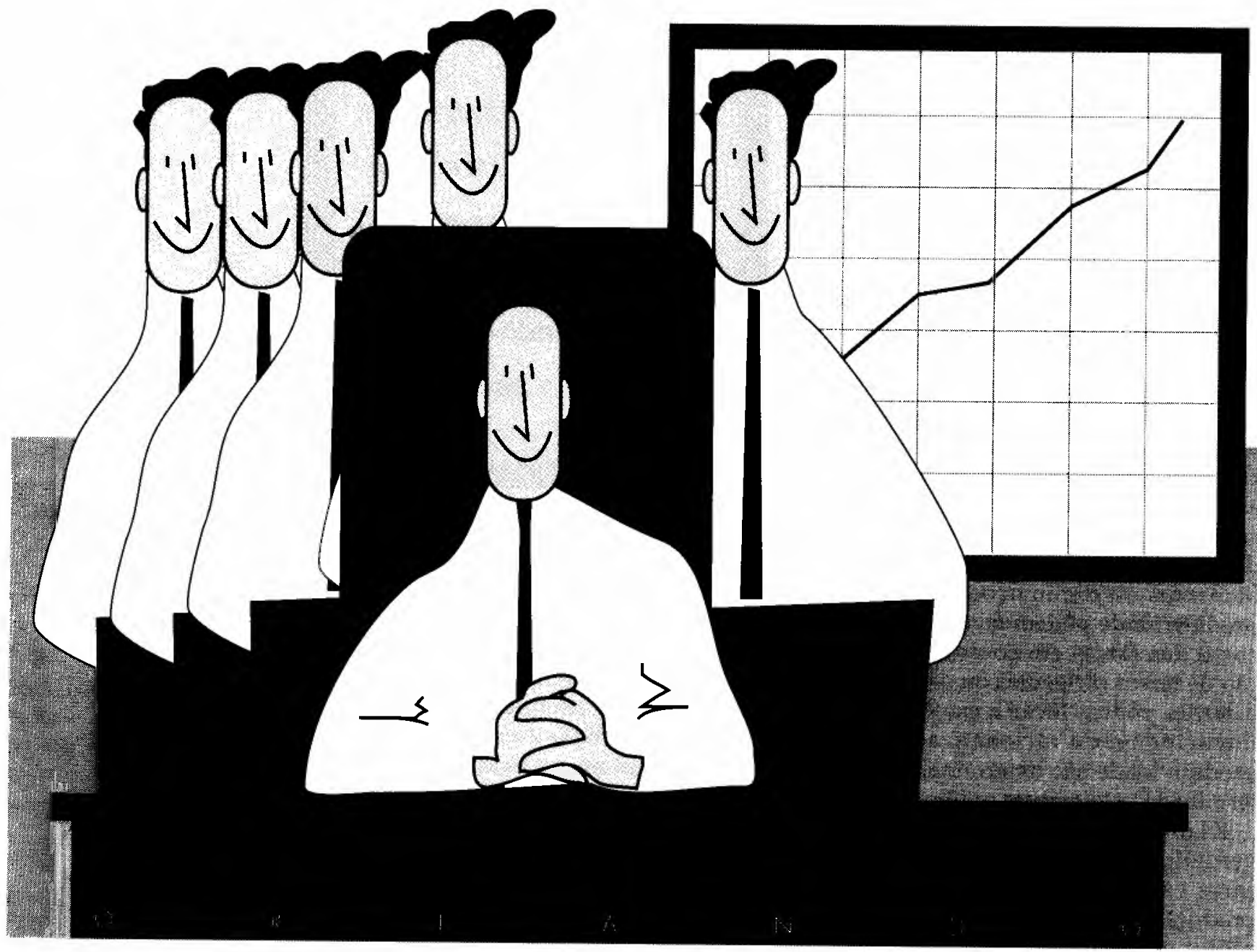

\title{
A RESPONSABILIDADE SOCIAL DA EMPRESA: UMA NOVA VANTAGEM COMPETITIVA*
}

- Carlos A. C. Ribeiro

Professor do Departamento de Planejamento e Análise Econômica Aplicados à Administração da EAESP/FGV.

* RESUMO: O artigo discute uma tendência no mundo empresarial - 0 aumento da responsabilidade da empresa para com suas partes constituintes: acionistas, empregados, clientes e comunidade. Observa-se que o maior grau de responsabilidade social tem estado associado a um melhor desempenho das empresas, podendo gerar inclusive uma vantagem competitiva. No entanto, a adoção por empresas brasileiras de filosofias corporativas em que esse princípio está presente é prejudicada devido às características culturais da sociedade brasileira.
* PALAVRAS-CHAVE: Filosofia corporativa, administração de vanguarda, padrões de excelência gerencial.

* ABSTRACT: This article discusses a trend in the business world - the increasing corporate responsibility to its contituencies: shareholders, employees, customers and community. The higher social corporate responsibility has been associated with a better performance: eventually, it may create a competitive advantage. Nevertheless, the adoption of this corporate philosophy by Brazilian corporations is harmed due to cultural characteristics prevalent in Brazilian society.

* KEY WORDS: Corporate philosophy, vanguard management, management excellence standards.

* Discurso proferido por ocasião da formatura da $63^{\mathrm{a}}$ turma do curso de Administração de Empresas de São Paulo da EAESP / FGV.

São Paulo, 33(1):46-50 Jan./Fev. 1993 
Na década de 70, em plena crise do petróleo, os principais executivos da General Motors (GM) acreditavam que a energia permaneceria barata e abundante, e a concorrência estrangeira nunca alcançaria mais do que $15 \%$ do mercado americano de automóveis. Negavam ainda a necessidade de produzir carros menores, mais econômicos e de qualidade superior. Havia entre os seus executivos a crença que o negócio da GM era ganhar dinheiro, e não fazer carros. ${ }^{1}$

A maior empresa manufatureira do mundo e um dos símbolos da grande corporação americana, a GM pode sentir no longo prazo os estragos dessas previsões. Isto, associado a sua incapacidade de responder rapidamente às mudanças do setor e do mercado, acarretaram em 1991 o prejuízo de US\$ 7 bilhões no mercado americano.

Para tentar reverter essa situação, a GM se vê obrigada a incorrer a um plano de redução de custos que prevê nos próximos quatro anos o fechamento de seis fábricas de montagem e 15 de peças, a demissão de 74 mil funcionários e o corte de US\$ 1,1 bilhão em gastos de capital. ${ }^{2}$ Tal fenômeno não está restrito à GM ou ao setor automobilístico; atinge também a pérola da coroa das grandes corporações americanas, a IBM. No ano passado, este mamute de 373 mil funcionários perdeu significativa parcela de mercado. No período entre 1985 e 1990 sua participação caiu de $30 \%$ para $21 \%$, num mercado onde cada ponto percentual representa algo em torno de US\$ 3 bilhões em vendas. ${ }^{3}$ Acompanhando a tendência, os lucros da IBM em 1991 retornaram aos mesmos níveis de início da década, isso numa indústria que cresce a rápidas taxas.

Concomitante ao processo de decadência das grandes corporações, o mercado acionário já faz suas apostas em relação às empresas do futuro. No bolo das apostas, o futuro parece estar em companhias como a Microsoft, empresa produtora de software, de 17 anos de idade, 10 mil funcionários e vendas no valor de US $\$ 1,8$ bilhão. $O$ valor de mercado de suas ações é de US\$ 22 bilhões, quase o mesmo montante do valor das ações da GM, uma empresa na casa dos setenta anos, $776 \mathrm{mil}$ funcionários e faturamento que atinge a estratosférica cifra de US\$ 123 bilhões. ${ }^{4} \mathrm{~A}$ desilusão do mercado com a IBM também é fato: o valor de mercado das ações da IBM no período 1985-91 foi reduzido em US\$ 42 bilhões, caindo de US\$ 99 bilhões em 1985 para US\$ 47 bilhões em 1991. ${ }^{5}$ Aparentemente, o mercado acionário decreta a morte das empresas ainda em vida.

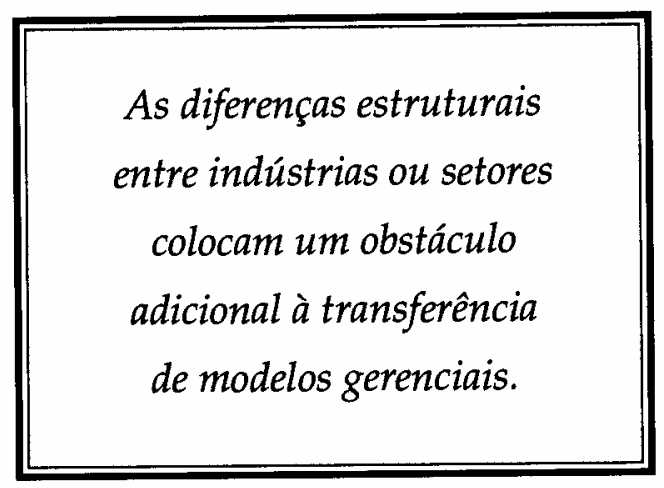

O ocaso de algumas corporações-símbolo indica que as empresas não são permanentes, que o capitalismo destrói suas empresas do mesmo modo que gera outras. Se comparados os dados da revista Fortune a respeito das 100 maiores empresas americanas nos anos de $1956 \mathrm{e}$ 1989, observa-se que mais de dois terços das empresas foram substituídas por outras de crescimento mais rápido.

Existe o reconhecimento de que mudanças são essenciais para evitar a estagnação e o desaparecimento; contudo, como bem coloca o comentarista Keith Hammonds ${ }^{6}$ da revista Business Week, "o problema é que nós freqüuntemente desejamos a mudança desde que não seja dolorosa". Hammonds comenta que em alguns casos o que a empresa necessita é um tapa na cara de um desconhecido, alguém com uma perspectiva "fresca" do problema. Em outras palavras, atribui-se ao executivo recém-chegado a tarefa de chacoalhar a empresa.

$\mathrm{Na}$ tentativa de deter o processo de degenerescência das empresas, os executivos têm procurado modelos de excelência gerencial, que não necessariamente se adequam às características de suas empresas, de seu setor ou mesmo da cultura de seu país. $O$ processo de degenerescência e a necessidade de mudanças também fazem parte da realidade das empresas
1. O'TOOLE, James. Vanguard Management. New York, Garden City, Doubleday, 1985, pp.5556.

2. TREECE, J. B. \& MILLER, K. L. "If the Japanese Were Running GM."Business Week. 27/01/1992, p. 20.

3. LOOMIS, Carol J. "Can John Akers Save IBM?" Fortune. $15 / 07 / 1991$, p. 29.

4. CAPITALISM's Creative Destruction. The Economist. 323(7753):17, 04/04/1992.

5. LOOMIS, Carol J. Op. Cit., p.27.

6. HAMMONDS, Keith. "Why Big Companies Are So Tough to Change" Business Week. 17/06/1992, pp.30-31. 
7. TREECE, J. B. \& MILLER, K. L. "If the Japanese Were Running GM." Business Week. Op. Cit.

8. b'TOOLE, James. Op. cit., p. 17.

9. WHYTE JR., William $H$. The Organization Man. New York, Simon and Schuster, 1956, $429 \mathrm{p}$. brasileiras. A incapacidade dessas empresas de responderem às mudanças do ambiente somente prenuncia um desfecho pouco favorável. Apesar da diferença de grau, os administradores brasileiros estão se defrontando com problemas de natureza semelhante.

À luz desses fatos, é necessário chamar a atenção para dois aspectos desse cenário: as dificuldades de transferência de práticas gerenciais e a administração de vanguarda e suas características.

\section{A TRANSFERÊNCIA DE PRÁTICAS GERENCIAIS}

Comecemos com as dificuldades na busca de um padrão de excelência gerencial. Num artigo da revista Business Week a respeito da crise da GM, a seguinte questão foi colocada: " $E$ se os japoneses estivessem gerenciando a GM?"7

Num momento em que as práticas gerenciais japonesas são transformadas em padrões de referência de administração, esta questão ganha relevância. No entanto, a questão suscita dúvidas quanto à possibilidade de transferência de práticas gerenciais bem-sucedidas entre empresas de culturas diferentes.

De fato, os analistas da Business Week confirmam a impossibilidade da aplicação de muitas das práticas japonesas ao caso americano, uma vez que implicariam a alteração de valores individuais. Apontam também que no Japão, devido aos keiretsu, a GM provavelmente nunca chegaria ao ponto em que chegou. Esses grupos industriais centrados ao redor de um banco intervêm em suas empresas antes que uma situação irreversível se instale.

A transferência de práticas gerenciais esbarra em outras duas dimensões ${ }^{8}$ do mundo empresarial: as diferenças entre os setores e as diferenças nas histórias das próprias empresas.

As diferenças estruturais entre indústrias ou setores colocam um obstáculo adicional à transferência de modelos gerenciais. Práticas gerenciais bem-sucedidas em setores de rápido crescimento, como a biotecnologia, podem ser inadequadas a setores como o siderúrgico, cuja dinâmica é bastante diferente. Mesmo em empresas do mesmo setor, diferenças na história de cada empresa podem ou não permitir a aplicação dessas práticas. $O$ fato da empresa ser familiar ou estar sob o comando de profissionais faz diferença no caso.

Uma análise superficial do problema revela que as soluções para cada empresa tendem a ser específicas, mas os princípios adotados pelas empresas podem ser gerais, aplicáveis a qualquer uma. Do

\begin{tabular}{|c|} 
As dificuldades enfrentadas \\
atualmente pelas corporações \\
americanas e, por extensão, pelas \\
empresas que se valem do modelo \\
de administração americano, \\
coincidem com o fim da era \\
do homem da organização. \\
\hline
\end{tabular}

mesmo modo que os países adotam constituições distintas, as empresas também; tal fato não impede, entretanto, que uma constituição seja melhor que outra, assim como certos princípios podem ser melhores que outros.

Falaremos a seguir sobre empresas que adotaram um conjunto de princípios que as diferenciam do grosso das empresas americanas, tanto em sua visão acerca do papel que a empresa deve desempenhar nos dias atuais, como em seu plano de desempenho.

\section{A ADMINISTRAÇÃO DE VANGUARDA}

As dificuldades enfrentadas atualmente pelas corporações americanas e, por extensão, pelas empresas que se valem do modelo de administração americano, coincidem com o fim da era do homem da organização. Celebrizado por William Whyte Jr. ${ }^{9}$, o homem da organização teve seu apogeu na década de 60, época de grande crescimento da economia americana, competição estrangeira incipiente e a existência de regulamentação em setores importantes, como por exemplo bancos, linhas aéreas e telecomunicações. Adequado a este ambiente econômico, o homem da organização representou uma geração de executivos sem rosto, avessos 
ao risco e apegados ao poder burocrático. Em contrapartida, a segurança e as recompensas da burocracia corporativa exigiam do indivíduo um compromisso com o anonimato e sua submersão na organização.

Mudanças no cenário econômico, como a intensificação da competição, o processo de desregulamentação e a emergência da nova economia de serviços põem em xeque o modelo de administração representado pelo homem da organização. Em seu lugar está surgindo a administração de vanguarda, segundo denominação do jornalista e professor James O'Toole. ${ }^{10}$ Não se trata de um conceito ideal, uma construção teórica, mas sim uma filosofia corporativa praticada por empresas como Motorola, Levi Strauss, Weyerhauser, empresas de semicondutores, vestuário, papel e celulose, entre outras.

Os praticantes dessa filosofia, os administradores destas empresas, seguem um conjunto de princípios específicos. Sem se estender muito sobre os princípios da administração de vanguarda há de se destacar alguns deles, por exemplo:

a. Os indivíduos se sobrepõem à organização. A participação dos funcionários nas decisões que os afetam, nos lucros que decorrem de aumentos de produtividade, e a preocupação com o treinamento contínuo desses funcionários constituem um compromisso dessas administrações. Neste tipo de organização, a meritocracia e o apego ao risco são alguns dos valores que regem a vida dos indivíduos;

b. A estabilidade de emprego é um objetivo, mesmo em tempos de recessão. Essas empresas têm se utilizado de mecanismos mais ou menos sofisticados para atingir este objetivo;

c. Os investimentos de longo prazo respondem por uma parcela importante do volume de investimentos dessas empresas; isto, apesar das pressões para a obtenção de resultados a curto prazo prevalecentes na economia americana. Por exemplo, a Control Data investiu US\$ 800 milhões no projeto PLATÃO, e somente começou a obter lucros do projeto 15 anos após o seu iní- cio. Os projetos de fazenda marinha da Weyerhauser levaram mais de dez anos para a geração de retornos. A Atlantic Richfield Company (ARCO), empresa de petróleo e químicos, despendeu alguns bilhões de dólares e esperou uma década antes que seus poços de petróleo em North Slope começassem a jorrar as primeiras gotas de lucro.

d. As empresas têm uma consciência social. A idéia central a este princípio é que cabe à empresa um papel maior que maximizar a riqueza de seus acionistas; a sua responsabilidade se expande e a empresa passa a responder também pelos funcionários, consumidores e a própria comunidade da qual faz parte. Decorre daí que os padrões convencionais de desempenho, como lucratividade e participação de mercado ficam limitados, pois fornecem somente uma dimensão da responsabilidade da empresa, aquela para com os seus acionistas.

\section{Mudanças no cenário econômico, como a intensificação da competição, o processo de desregulamentação e a emergência da nova economia de serviços põem em xeque o modelo de administração representado pelo homem da organização.}

A maior responsabilidade social da empresa tem sido incorporada a seu dia a dia das mais diversas formas. Por exemplo, a Levi Strauss tem uma das maiores fundações entre as grandes corporações americanas. Parte dos recursos da Fundação é distribuída anualmente à organizações comunitárias. As decisões acerca dos beneficiários dos recursos fica a cargo dos funcionários, membros dessas comunidades. A propósito, a Levi Strauss conta com 111 fábricas espalhadas por 17 países.

A ARCO liderou na década de 70 a luta pela conservação de energia, ao mesmo tempo que exibia elevados níveis de
10. O'Toole, James. Op. cit. 
11. DRUCKER, Peter F. Uma Era de Descontinuidade. Rio de Janeiro, Zahar Editores, $3^{\mathbf{a}}$ edição, $1976,427 p$

12. FAORO, Raymundo. "A Questão Nacional: a modernizacão". Paper apresentado em 30/3/92 ao Instituto de Estudos Avançados da Universidade de São Paulo. proteção ambiental e saúde ocupacional. Por sua vez, a Control Data, uma empresa produtora de hardware, possui uma política de instalar todas as suas novas fábricas em guetos urbanos.

Esses exemplos não se esgotam aqui, e servem como contraste ao caso da GM e

\begin{tabular}{|c|}
\hline \\
Empresa moderna é aquela que \\
trabalha a favor do tempo, aquela \\
na qual os administradores \\
concebem a administração \\
enquanto um processo contínuo \\
de resposta a um ambiente \\
mutável, a necessidades e \\
oportunidades econômicas. \\
\hline
\end{tabular}

IBM. Contudo, o que deve ser destacado é que são essas as empresas que apresentam desempenho superior em comparação ao de suas rivais e, portanto, tendem a tornar-se padrões de excelência gerencial.

Se, por um lado, os administradores de vanguarda imprimem um padrão de desempenho superior às suas empresas, por outro lado fica a questão se haverá empresas com filosofias corporativas semelhantes no cenário brasileiro em futuro próximo.

Desnecessário dizer que o princípio de mais difícil implantação no caso das empresas brasileiras é o da responsabilidade social, devido às características culturais da sociedade brasileira e das filosofias corporativas prevalecentes entre as empresas brasileiras, que colocam os interesses dos acionistas em primeiro lugar, em detrimento de suas outras partes constituintes. Uma mudança deste estado de coisas deve enfrentar sérias resistências internas por parte dos principais beneficiários: os acionistas.

\section{A ERA DAS MUDANÇAS}

Peter Drucker ${ }^{11}$, em seu livro Uma Era de Descontinuidade, observa que atravessamos um "período de mudanças na tecnologia e na política econômica, nas estruturas industriais e na teoria econômica, no conhecimento necessário à Administração e ao governo e nos problemas econômicos." Ora, esse cenário não constitui novidade; o interessante é verificar como as diferentes nações têm se posicionado diante desse cenário comum.

Diferentes civilizações têm maneiras distintas de travar a luta contra o tempo. Nas palavras do economista chinês Anthony Chan, ao comentar a economia de seu país, menciona que o comunismo chinês já desistiu de fazer o relógio andar para trás. Fazendo um contraponto, o jurista Raymundo Faoro ${ }^{12}$, comentando a trajetória brasileira rumo à modernidade sugere um movimento semelhante ao de um "relojoeiro que, para alcançar o meio dia ao nascer do sol, adianta o relógio, trapaceando o espectador e trapaceando-se a si mesmo".

No Brasil, tenta-se dar um "jeitinho" inclusive no tempo. No entanto, é necessário reconhecer que o tempo tem sido mais forte que os homens e as empresas, e está a todo instante a mostrar-lhes a sua condição transitória. Faoro observa ainda que "o relógio da história não tem um curso fatal, nem admite a queima de horas, contra o tem$p o^{\prime \prime}$. Em outras palavras, sugere que o rumo à modernidade não admite atalhos.

Neste contexto, empresa moderna é aquela que trabalha a favor do tempo, aquela na qual os administradores concebem a administração enquanto um processo contínuo de resposta a um ambiente mutável, a necessidades e oportunidades econômicas; e não enquanto a aplicação de um conjunto de soluções pré-fabricadas a um problema específico.

Isso nos leva a uma consideração final. A introdução de uma nova postura de administração baseada na experiência das empresas de vanguarda americanas constitui o desafio da nova geração de administradores. Existe um papel social que deve ser desempenhado por intermédio das empresas. Portanto, ao introduzir uma nova filosofia gerencial, esses administradores estarão não somente modernizando suas empresas como também contribuindo para a modernidade do país.

Aproveitando as palavras de Keith Hammonds, talvez seja hora das empresas brasileiras levarem um tapa. Eis o desafio dos novos administradores. 